OAK RIDGE NATIONAL LABORATORY

MARTIN MARIETTA

\section{W-12 Valve Pit Decontamination Demonstration}

\author{
RECEIVED \\ MAR 131996 \\ OSTI
}
C. E. Benson
J. E. Parfitt
B. D. Patton 
This report has been reproduced directly from the best available copy.

Available to DOE and DOE contractors from the Office of Scientific and Technical Information, P.O. Box 62, Oak Ridge, TN 37831; prices available from (615) 576-8401, FTS 626-8401.

Available to the public from the National Technical Information Service, U.S. Department of Commerce, 5285 Port Royal Rd., Springfield, VA 22161.

This report was prepared as an account of work sponsored by an agency of the United States Government. Neither the United States Government nor any agency thereof, nor any of their employees, makes any warranty, express or implied, or assumes any legal liability or responsibility for the accuracy, completeness, or usefulness of any information, apparatus, product, or process disclosed, or represents that its use would not infringe privately owned rights. Reference herein to any specific commercial product, process, or service by trade name, trademark, manufacturer, or otherwise, does not necessarily constitute or imply its endorsement, recommendation, or favoring by the United States Government or any agency thereof. The views and opinions of authors expressed herein do not necessarily state or reflect those of the United States Government or any agency thereof. 
Chemical Technology Division

\section{W-12 VALVE PIT DECONTAMINATION DEMONSTRATION \\ C. E. Benson \\ J. E. Parfitt \\ B. D. Patton}

Date Published: December 1995

Prepared by

OAK RIDGE NATIONAL LABORATORY

Oak Ridge, Tennessee 37831-6285 managed by

LOCKHEED MARTIN ENERGY SYSTEMS, INC.

for the

U.S. DEPARTMENT OF ENERGY

under contract DE-AC05-84OR21400 


\section{CONTENTS}

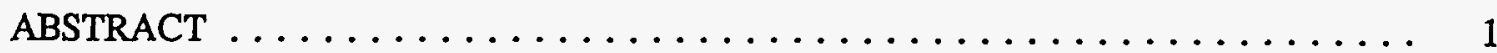

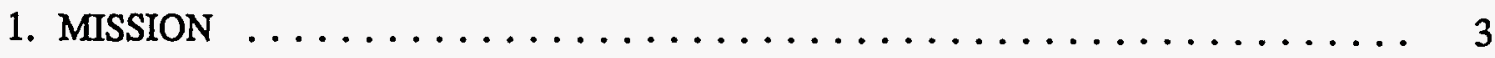

2. ROBOTICS DESIGN $\ldots \ldots \ldots \ldots \ldots \ldots \ldots \ldots \ldots \ldots \ldots \ldots \ldots$

3. DECONTAMINATION DEMONSTRATION $\ldots \ldots \ldots \ldots \ldots \ldots \ldots$

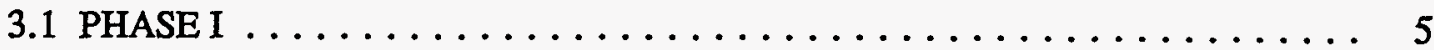

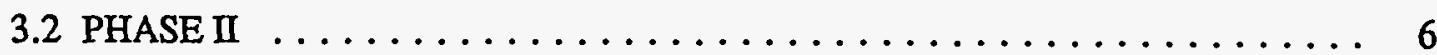

3.3 HEALTH PHYSICS SURVEY DATA . . . . . . . . . . . . 8

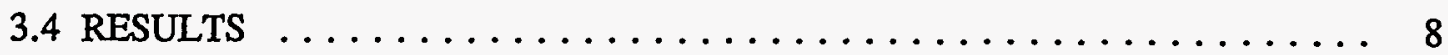

4. KEY PROJECT DELIVERY . . . . . . . . . . . . . . . 9

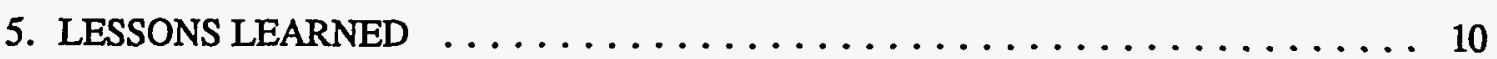

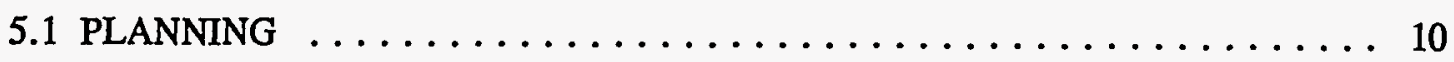

5.2 DECONTAMINATION OPERATION $\ldots \ldots \ldots \ldots \ldots \ldots \ldots \ldots$

5.3 PROJECT MANAGEMENT $\ldots \ldots \ldots \ldots \ldots \ldots \ldots \ldots \ldots \ldots$

5.4 CONCLUSIONS $\ldots \ldots \ldots \ldots \ldots \ldots \ldots \ldots \ldots \ldots \ldots \ldots \ldots \ldots \ldots$ 



\title{
W-12 VALVE PIT DECONTAMINATION DEMONSTRATION
}

\author{
C. E. Benson \\ J. E. Parfitt \\ B. D. Patton
}

\begin{abstract}
Waste tank W-12 is a tank in the ORNL Low-Level Liquid Waste (LLLW) system that collected waste from Building 3525. Because of a leaking flange in the discharge line from W-12 to the evaporator service tank (W-22) and continual inleakage into the tank from an unknown source, W-12 was removed from service to comply with the Federal Facilities Agreement requirement. The initial response was to decontaminate the valve pit between tank W-12 and the evaporator service tank (W-22) to determine if personnel could enter the pit to attempt repair of the leaking flange. The pit is located west of Fourth Street (across the street from the southwest corner of Building 3525) and measures $\sim 12 \mathrm{ft}$ long, $3 \mathrm{ft}$ wide, and $8 \mathrm{ft}$ deep. The W- 12 jet system occupies approximately one-half the length of the pit.

Radiation levels taken previously were $\sim 15 \mathrm{R} / \mathrm{h}$ at the bottom of the pit. Due to the uncertainty of the radiation exposure in the pit, Health Physics lowered thermoluminescent dosimeters into the pit ( $~ 6$ in. from the bottom of the pit) to determine radiation exposure levels. The results of this measurement indicated radiation fields of $200 \mathrm{mR} / \mathrm{h}$ (skin) and $2 \mathrm{R} / \mathrm{h}$ (penetrating).

Preventing the spread of radioactive contamination from the pit to the environment and to other waste systems was of concern during the decontamination. The drain in the pit goes to the process waste system; therefore, if high-level liquid waste were generated during decontamination activities, it would have to be removed from the pit by means other than the available liquid waste
\end{abstract}


connection. In addition, the radioactive contamination had been present in the pit for a long time and could have been absorbed into the concrete. It was questionable whether surface decontamination could reduce the radiation exposure enough, given the proposed level of effort and limit on waste generated. However, decontamination could reduce the exposure to a level such that temporary shielding could be used to lower the exposure to a reasonable level for a person to enter the pit.

The decontamination objective was to reduce the current loose contamination level to an ALARA condition. Survey analysis was used to determine additional decontamination to be performed. Initial Health Physics analysis of radiation surveys indicated all decontamination activities must be conducted using remote operations.

Remote decontamination of W-12 was conducted using the General Mills manipulator bridge and telescoping trolley and REMOTEC RM-10 manipulator. The assembly required locator rails for the bridge. Also, special fittings and hardware were required to adapt HEPA vacuum attachments for operation by an RM-10 manipulator. A mockup was constructed and the assembly tested before attempting activities at the $\mathrm{W}-12$ valve pit.

The initial objective of repairing the leaking flange was not conducted because of the repair uncertainty and the unknown tank inleakage. Rather, new piping was installed to empty the W-12 tank that would bypass the valve pit and eliminate the need to repair the flange.

The radiological surveys indicated that a substantial decontamination factor was achieved. The readings indicated that the activity level was reduced by removing large items from the pit; however, the bulk of the contamination was reduced by extracting the silt from the floor of the pit using the HEPA vacuum system. The decontamination effort was concentrated in the area immediately under the leaking flange. The highest radiation level was reduced from $15 \mathrm{R} / \mathrm{h}$ to $8 \mathrm{R} / \mathrm{h}$ (decontamination factor of 1.9 ; percentage activity removed, $47 \%$ ). The other areas were slightly 
reduced or remained the same following the removal of the large items, but the vacuum system was not used in these areas. The decontamination demonstration showed that the level of radioactive contamination could be reduced to allow personnel access to make repairs. The fixed contamination in the concrete floor of the pit could have been removed; however, temporary shielding could instead be placed over the contaminated area and reduce the radiation levels sufficiently to allow personnel entry for repair operations.

\section{MISSION}

The Federal Facilities Agreement (FFA) between the Oak Ridge National Laboratory (ORNL), the Department of Energy (DOE), the Tennessee Department of Health and Environment (TDHE), and the Environmental Protection Agency (EPA) established new operating and integrity testing requirements for the ORNL Liquid Low-Level Waste (LLLW) System that supports the facilities. Tank systems that either had known inleakage or had not definitely passed systems integrity tests were required to be shut down within $24 \mathrm{~h}$ of the effective date of the FFA. Waste tank system W-12, which collected waste from Building 3525 , had a leaking flange in the discharge line in the valve pit between tank W-12 and the evaporator service tank (W-22), and corrective action for repair of the leaking systems had been initiated prior to the signing of the FFA. An immediate decision was made to attempt to repair the leaking flange, but it was necessary to decontaminate the valve pit to determine if personnel could enter the pit to make the repair. The decontamination objective was to reduce the loose contamination level to ALARA condition, after which a survey analysis would determine if additional decontamination would be necessary. A preliminary Health Physics analysis of radiation surveys indicated that all decontamination activities had to be conducted using remote 
operations. The initial objective to repair the leaking flange was not conducted because of the repair uncertainty and the unknown tank inleakage. Rather, piping was installed to empty the W-12 tank that would bypass the valve pit, thus eliminating the need to repair the flange. However, the FFA project personnel resolved to continue the decontamination to develop and demonstrate our remote capabilities and gain experience on an inactive system before it became necessary to address an active one.

\section{ROBOTICS DESIGN}

Remote decontamination of the W-12 valve pit was designed to be conducted using a General Mills (GM) bridge and telescoping trolley that was salvaged from the Oak Ridge Research Reactor (ORR) to position a two-arm manipulator (REMOTEC RM-10), which was surplused from the HighRadiation-Level Examination Laboratory (HRLEL). The assembly consisted of two gantry cranes connected by two crane rails that provided the track for the GM bridge. Special tools, fittings, and hardware for the HEPA vacuum attachments were required for the material removal operation that was to be conducted by the RM-10 manipulator. A mockup was constructed and the assembly tested before attempting activities at W-12 valve pit. Modifications were made to the manipulator system to improve operability as a result of the mockup testing.

\section{DECONTAMINATION DEMONSTRATION}

The containment tent and the decontamination equipment were installed at the W-12 site, and the equipment troubleshooting was completed prior to opening the valve pit. There was some difficulty with the RM-10 manipulator during the troubleshooting, but after a representative from REMOTEC checked the system and did some repairs, it appeared to be operating correctly. The 


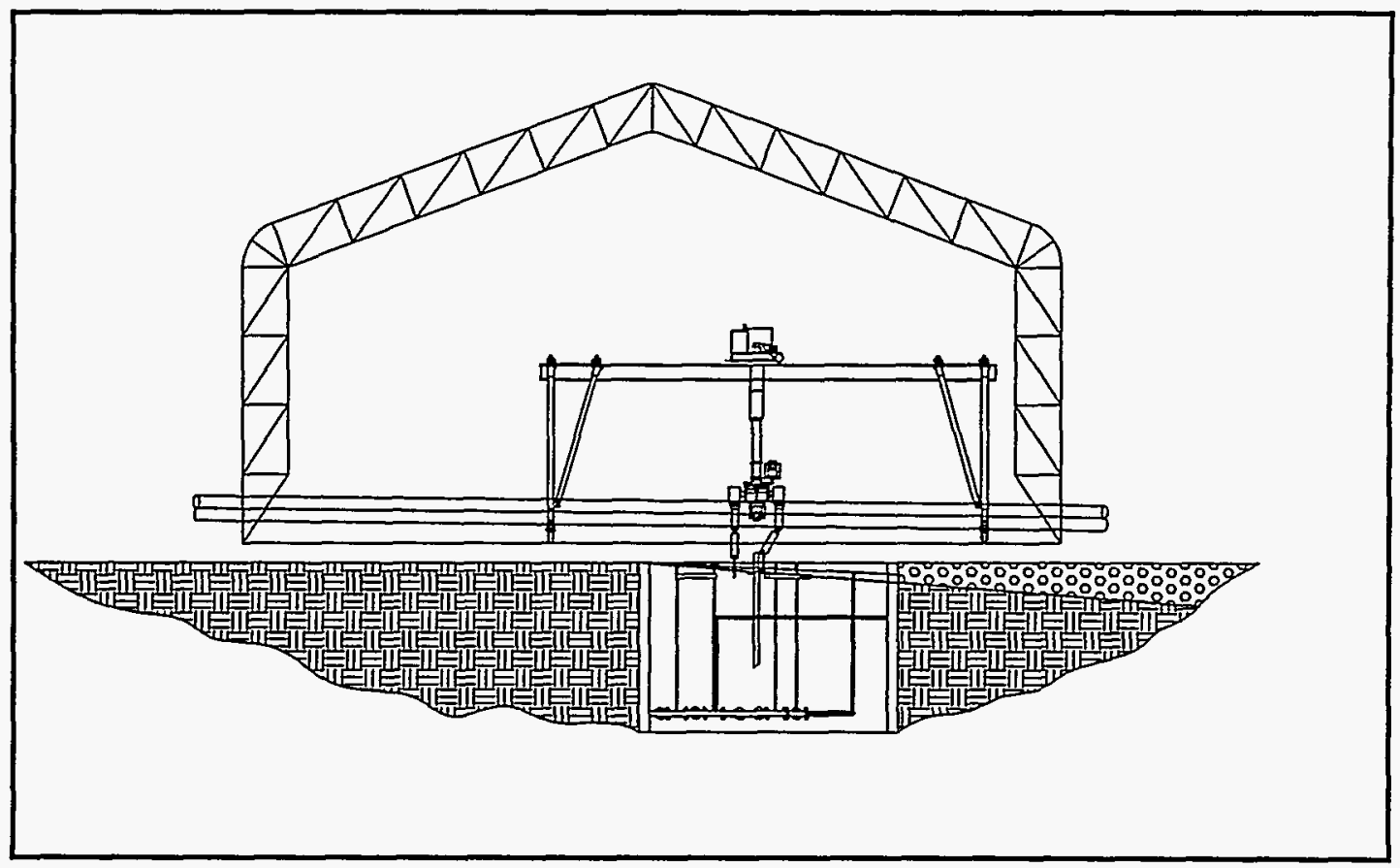

Fig. 1. Robotics assembly elevation.

pre-decontamination HP survey of the valve pit was completed, and the results indicated that most of the radiation dose was from the pit floor. A reading taken around the pipe was $\sim 2 \mathrm{R} / \mathrm{h}$, but readings taken on contact with the pit floor were $15 \mathrm{R} / \mathrm{h}$. It was thought that the debris that was vacuumed from the pit could approach the $15-\mathrm{R} / \mathrm{h}$ level. To ensure proper packaging of waste, an isotopic analysis (gamma spectrometry) was conducted prior to initiating debris removal. The primary reason for the analysis was to determine the curie content so that an appropriate disposal method could be selected.

\subsection{PHASE I}

The decontamination of the $\mathrm{W}-12$ valve pit began by removing the ladders and other large pieces of debris using specialty tools designed for use with the manipulator assembly. The RM-10 
manipulator proved to be a very sensitive piece of equipment whose electronics were not designed to endure the extreme weather conditions to which it was subjected. Temperatures reached in excess of $100^{\circ} \mathrm{F}$ in the containment enclosure. The physical size of the RM-10 and its numerous valve extension handles and support bars made working within the narrow valve pit very cumbersome. The operation was very tedious and time consuming. The radiation levels were monitored continually and indicated that personnel equipped with the proper protective equipment could assist the operation of the manipulator. The assistance did expedite the decontamination activities, and personnel did not receive unacceptable radiation exposure.

The capabilities of the manipulator assembly demonstrated that the robotics can accomplish the decontamination task if necessary. The lessons learned from this experience could provide valuable information for those dealing with an emergency situation requiring remote operations. Although removal of all material from the pit using only the manipulator assembly would have been beneficial experience for the operators, it was decided that it would delay timely completion of the decontamination task.

\subsection{PHASE II}

Following evaluation of the equipment and the level of radiation exposure of the first phase of the demonstration, the method for completion of the task was determined to be as follows:

1. Special tools would be fabricated to allow personnel to position large objects in an open area in the pit where they could be placed in a container for removal or storage.

2. The remaining material would be vacuumed using the manipulator with assistance of personnel using special tools for positioning the nozzle. 
3. All operations performed by personnel were conducted outside the pit; hence, confined space requirements would not have to be addressed.

Evaluation of the second phase of the demonstration identified limiting conditions for continuing the decontamination activities. The contamination located in/on the concrete below the leaking flange was producing the predominant dose from the $\mathrm{W}-12$ pit. The focus of the decontamination effort was to reduce the dose rate for possible repair of the flange. The large pieces of debris were moved or collected from the high radiation area to allow access for the vacuum hose. A portion of the pit around the leaking flange was vacuumed, and the dose rate was reduced. However, it was determined that the contamination is fixed in the concrete. The vacuum operation produced an elevated radiation reading in the vacuum hose, and during removal of the material, the personnel assisting with the vacuum system received a higher-than-expected radiological exposure. Transferrable contamination was detected outside the pit, so a spot survey of the vacuum system was immediately conducted. The survey indicated there was no problem with the vacuum equipment and hose; hence, it was concluded that the airborne contamination had resulted from disturbing the extremely high levels of contamination inside the pit. A complete survey of the pit and all areas inside the tent was conducted to determine the extent to which the contamination had spread. The results indicated that the radiation dose in the area under the leaking flange had been reduced from $15 \mathrm{R}$ to $8 \mathrm{R}$, but the flange continued to have a slow leak. The survey also indicated airborne contamination, and all smears taken inside the exclusion area indicated trace contamination, but no contamination was detected outside the controlled area. 


\subsection{HEALTH PHYSICS SURVEY DATA}

The radiological surveys indicated that a substantial decontamination factor had been achieved. The level of activity had been reduced by removing large items from the pit; however, most of the contamination was reduced by extracting the silt from the floor of the pit using the HEPA vacuum system. The decontamination effort was concentrated in the area immediately under the leaking flange. The highest radiation level was reduced from $15 \mathrm{R} / \mathrm{h}$ to $8 \mathrm{R} / \mathrm{h}$ (decontamination factor of 1.9 ; percentage activity removed, $47 \%$ ). The other areas were slightly reduced or remained the same following the removal of the large items, but the vacuum system was not used in those areas. The decontamination demonstration showed that the level of radioactive contamination could be reduced to allow personnel access to make repairs. The fixed contamination in the concrete floor of the pit could be removed; however, temporary shielding could instead be placed over the contaminated area to reduce the radiation levels to permit personnel entry for repair operations.

\subsection{RESULTS}

Following the evaluation of the radiation survey, the decision was made to discontinue the decontamination activities inside the pit. The objectives of the demonstration had been accomplished, and the lessons learned would be valuable for other highly contaminated valve pits or other systems which must be addressed with similar decontamination requirements. It was decided that the leaking flange would be sealed outside the W-12 pit. The cleanup of the decontamination equipment and the general area inside the exclusion zone was completed, and the waste was packaged in a B-25 box. The tent area was considered a contamination area until final decontamination activities were completed and the tent and tent area were released. 
The results of this work indicate that the use of field-deployed, remotely operated decontamination systems is a feasible approach for decontamination and decommissioning of highly contaminated facilities. Design improvements are necessary to enhance the flexibility of the remote systems, thereby enhancing capabilities, reducing the time requirement, and reducing costs.

\section{KEY PROJECT DELIVERY}

The key project deliverables were as follows:

- Decontamination Plan and drawings of the W-12 decontamination demonstration facility

- Salvage/Removal of GM from the ORR

- Modification of the GM to be used with the W-12 gantry assembly

- Salvage of the REMOTEC RM-10 manipulator

- Design and fabrication of the robotics assembly

- Approved Robotics assembly erection and take-down procedures

- Approved Problem Safety Summary

- Approved Site Safety and Health Plan

- HEPA vacuum system

- Tent enclosure $(36 \times 32 \mathrm{ft})$

- Decontamination Demonstration

- Demonstration Evaluation

- Draft Final Report 


\section{LESSONS LEARNED}

\subsection{PLANNING}

The following are lessons learned from the different phases of the project.

- The Waste Management Plan should deal with the worst-case projections regarding waste volume and radioactivity of waste generated by the activity to ensure the waste can be handled efficiently (timely and cost-effectively).

- It is very important to have a detailed survey of both radiation contamination and a physical description of objects or equipment requiring removal or decontamination. Special tools and. fixtures must be available to address each item.

- Plan to perform only what is necessary and reasonable for $D \& D$, taking into account the end use of the facility or equipment. .

- A well-defined scope of work is necessary to define the required documentation.

- A more precise radiation survey will result in more appropriate safety requirements.

- Have specific objectives that are well defined before engaging a highly contaminated area.

- An accurate, detailed mockup would be beneficial for defining operational capabilities, ALARA concerns, and cost evaluation of the project.

\subsection{DECONTAMINATION OPERATION}

- Manipulator must be designed for the task and environment. The salvaged unit was adequate for the demonstration but would be more suited for detailed repair work than for gross decontamination work. 
- Containment is difficult when dealing with a grossly contaminated pit. Excess movement in the pit should be controlled to minimize disturbance of the particulate contamination, thereby limiting airborne activity.

- All material and equipment within the exclusion zone should be covered to minimize decontamination in the event of airborne contamination.

- The remotely handled tools and manipulator need substantial support to permit accuracy of operation. The mass of the manipulator and/or tools should be concentrated at or near the base of support, and the range of equipment extension should be limited.

- Areas with obstructions (supports, valve extension handles, several pipes, etc.) do not lend themselves easily to the dry decontamination method. Inadvertent contact with the obstructions create an excess of airborne contamination. Decontamination activity should be limited to a specific area for a specific task to minimize excessive airborne activity.

- Some of the operation could not be done totally remotely and required personnel to assist the manipulator-arm operation within the containment area. To minimize personnel assistance, specialty equipment should be designed for a specific operation. The capital cost will be compared to the personnel radiation exposure savings.

- Hook tools have limited use in remote operations. Specially designed tools are needed for attaching to and supporting objects.

\subsection{PROJECT MANAGEMENT}

- The management interfaces necessary for accomplishing a task should be minimized. The number of people involved in the communication chain should be minimized to make execution more effective. 
- Management needs:

- more detailed plans

- a well-defined line of communication

- a strict schedule for task completion

- To accomplish a task in a specified time frame, all supporting members must be involved, and the task leader must have the authority to require a timely response for all required activities.

- Task must be closely supervised to ensure the scope of work is carried out and documented.

\subsection{CONCLUSIONS}

- Complete decontamination is questionable for any pit such as W-12. The ALARA concerns far outweigh the benefits to the environment.

- Decontamination should be limited to that which is necessary to accomplish a specific task.

- We now have the robotics equipment and procedures. The RM-10 should be used only for a specific task and must have the appropriate environment and an adequate area in which to operate.

- The results of this demonstration exemplify the obstacles and concerns when conducting a remote decontamination operation in a highly contaminated facility. The resulting recommendations are 1. to confine decontamination operations to that which is necessary to support a specific maintenance or construction activity,

2. to stabilize contamination in place to prevent its spread to the environment, and

3. to limit complete decontamination activities to facilities or areas that are slated for unrestricted use. 


\section{INTERNAL DISTRIBUTION}

1-2. C. E. Benson

3. J. S. Davidson

4. T. E. Kent

5. L. E. McNeese

6. B. D. Patton

7. J. E. Parfitt

8. D. E. Reichle

9. S. M. Robinson
10. R. C. Stewart

11. Central Research Library

12. ORNL-Y-12 Technical Library Document Reference Center

13-14. ORNL Laboratory Records

15. ORNL Laboratory Records-RC

16. ORNL Patent Section

\section{EXTERNAL DISTRIBUTION}

17. C. E. Pepper, Department of Energy, WMTD, 3 Main, Oak Ridge, TN 37830

18-19. Office of Scientific and Technical Information, P.O. Box 62, Oak Ridge, TN 37831 


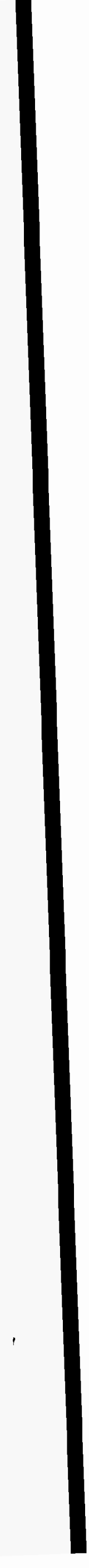

